\title{
Modernización y naturaleza. Auge y declive de la hacienda cañera y de fincas cafetaleras en el distrito de Teotitlán del Camino, Oaxaca, 1888-1917
}

Modernization and Nature. Rise and decline of the sugar cane Hacienda and private coffee plantations in the Teotitlán del Camino district, Oaxaca, 1888-1917

Marco Aurelio Almazán Reyes

Facultad de Antropología, Universidad Autónoma del Estado de México, México

ctassarma@yahoo.com.mx

\section{RESUMEN:}

Los análisis de la aplicación de las políticas liberales decimonónicas sobre tierras y aguas en México han considerado primordialmente variables sociopolíticas y económicas para explicar sus repercusiones en los ámbitos regionales. El propósito del presente artículo es sumar la observación de la influencia de la naturaleza en los resultados de esas políticas, particularmente en el distrito de Teotitlán del Camino, Oaxaca. Mediante la identificación de lo acaecido en sus dos espacios socionaturales, conformados por características distintivas, se ilustrará que la naturaleza posibilitó el impulso de proyectos cañeros y cafetaleros privados, pero también constituyó un actor principal en su posterior declive.

Palabras clave: Desamortización, Modernización, Reformas liberale, Reformas liberales, Federalización de aguas, Naturaleza, México.

\section{ABstract:}

The studies of liberal land and water policies of the 19th century in Mexico have primarily considered socio-political and economic factors to explain their repercussions in regional areas. The purpose of this article is to add the observation of the influence of nature on the results of such policies, particularly in the district of Teotitlán del Camino, Oaxaca. By identifying what happened in its two socionatural spaces, made up of distinctive characteristics, it will be illustrated that nature enabled to promote private cane and coffee projects, but also constituted a main actor in their subsequent decline.

KEYWORDS: Desamortizacion, Modernization, Liberal reforms, Federalization of water, Nature, México.

\section{INTRODUCCIÓN}

La aplicación de las reformas liberales decimonónicas sobre tierras y aguas en México ha sido objeto de numerosos e ilustrativos estudios enfocados en distintas latitudes de su territorio, los cuales han dado cuenta de la variedad de posturas y acciones de actores sociales que incidieron en sus también diversos resultados. De tales trabajos, los realizados en las últimas tres décadas (por ejemplo Buve y Falcón, 1998; Falcón, 2006; Escobar Ohmstede, 2012) han ofrecido una imagen matizada, en "escala de grises", respecto de la que se había vertido en "blanco y negro" en análisis de la primer mitad del siglo pasado (Tannenbaum, 2003; Molina, 1909/2016) ${ }^{1}$. En estos últimos había predominado la tendencia a ubicar a indígenas y campesinos como los actores perdedores luego de la aplicación de la legislación sobre división y adjudicación de las tierras comunales, pues, con base en ella, hacendados, terratenientes y agroempresarios les habrían arrebatado extensas tierras y recursos implícitos. En contraste, la historiografía de las últimas décadas, enfocada en mayor grado a observar dinámicas regionales y locales, ha identificado que no siempre fue así, ya que en no pocas ocasiones los habitantes de los pueblos contaron con amplios márgenes de acción durante la aplicación de la ley, por ejemplo, cuando pudieron evitar perder parte de sus recursos naturales ante interesados privados, o incluso cuando se beneficiaron con la obtención de tierras privadas para incorporarlas a su régimen comunal 
(Schenk, 1995). De manera implícita, los terratenientes no siempre fueron omnipotentes en su competencia con ayuntamientos o pueblos por controlar tierras, bosques o aguas. Tampoco lo fue el Estado en su intento de modernizar al sector agrario mediante la gestación y aplicación de la novedosa legislación, lo cual se debió a sus propias limitaciones institucionales y a resistencias locales (Buve y Falcón, 1998), como fue el caso de las leyes dirigidas a la privatización de tierras, a partir de 1856, y a la federalización de aguas, desde junio de $1888^{2}$.

En este artículo se analiza la puesta en marcha de tales leyes en algunos de los 26 pueblos que constituían el distrito antiguamente llamado de Teotitlán del Camino (situado al noroeste del estado de Oaxaca, en un área que limita con los estados de Puebla -al norte- y Veracruz - al noreste-), pero se agrega el rol que en esa coyuntura, y en procesos consecuentes, jugó la naturaleza. Los asentamientos de ese distrito se distribuían en dos espacios bien diferenciados: el constituido por tierras bajas, semiáridas y de clima cálido conocido como la Cañada, y el de altas y húmedas superficies, de temperatura templada y fría, denominado la Sierra Mazateca. Las características geográficas y naturales de ambos delinearon, desde épocas previas, dinámicas productivas y sociales, mientras que ya en las dos últimas décadas decimonónicas influyeron los resultados de las reformas liberales ya aludidas, cuyos efectos se prolongaron al menos hasta la segunda década del siglo XX.

Algunos estudios históricos agrarios ya han enfatizado la importancia de observar los pisos ecológicos en la competencia de actores sociales por el territorio, por ejemplo, en el municipio de Chalco durante el porfiriato (Tortolero, 1996), también durante la desamortización de tierras comunales y la reforma agraria en Lerma y Ocoyoacac (Camacho, 2015), o en la subcuenca del río Cuautitlán en torno a 1856-1917 (Neri, 2017) todos acaecidos en el estado de México ${ }^{3}$-. Si bien esos trabajos muestran que las características naturales de espacios concretos influyeron en el interés de grupos sociales por conseguir recursos considerados de valía productiva y comercial, en este estudio refiero a la naturaleza no sólo como contexto para el desarrollo de acciones humanas sino también como actor -a partir de la perspectiva de Stefania Gallini (2005, p. 99)-, dado que su accionar, acorde a características distintivas en los espacios geográficos, influyó en los resultados del programa liberal aquí analizado. Es decir, no sólo suscitó que sectores sociales se interesaran en algunos recursos y los explotaran, sino que su composición incidió, en conjunto con factores económicos y políticos, en los resultados de los procesos ahí desarrollados. Debido a esa perspectiva también se diferencia de otros que han analizado los resultados de las leyes liberales en la misma época en distritos o espacios contiguos, como el de Cuicatlán (Mendoza, 1998) y la Mixteca (Mendoza, 2011), en los que se ha enfatizado la vertiente de la resistencia y la negociación política para explicar los resultados relativos de la modernización y de la desamortización de tierras comunales.

La mencionada perspectiva aquí empleada es afín a la que ha sido desarrollada, por ejemplo, en una veta de la Historia ambiental estadounidense (Stewart, 1991; Fiege, 1999; Foltz, 2003; Nash, 2005), así como de la latinoamericana (Gallini, 2005; Pérez, 2001), que ha mostrado, en distintos contextos, cómo es que diversos procesos sociales se han tenido que ajustar a las condiciones establecidas por la naturaleza, a pesar de la supuesta predominancia del ser humano sobre ella. Dentro de esta vertiente se ha señalado que ese actor tiene sus propias lógicas de acción y reacción a través de las cuales condiciona y/o altera dinámicas productivas y, por ende, económicas y políticas. Análisis de ese tipo contradicen la imagen de la naturaleza como un "actor derrotado", comúnmente explotado y moldeado por la esfera humana; un enfoque al que se la denominado como declensionist en la historiografía estadounidense (Hughes, 2016) ${ }^{4}$. En el caso aquí abordado se ilustrará que el proceso de modernización en el distrito teotiteco incluyó intentos estatales y privados por implementar proyectos comerciales de gran escala, empleando para ello las leyes sobre federalización de aguas - la hacienda cañera-, y sobre división de tierras comunales -las fincas cafetaleras-. A su vez, aunados a factores sociales y políticos, tales proyectos fueron impactados por distintos elementos de la naturaleza, de modo tal que no lograron concretarse en la medida en que se idearon por parte de la élite política y económica. Por tanto, tales elementos también influyeron en el cambio social que se suscitó debido al declive de la 
producción basada en la "gran propiedad", y a la adopción de cultivos comerciales por parte de habitantes de algunos pueblos teotitecos.

\section{EL DISTRITO DE TEOTITLÁN DEL CAMINO A FINALES DEL SIGLO XIX E INICIOS DEL SIGLO XX}

Durante la segunda mitad del siglo XIX, el distrito de Teotitlán del Camino conjuntaba 26 pueblos, con ayuntamiento, dos haciendas, y media decena de ranchos, distribuidos en dos espacios geográficos, diferenciados por su altitud y composición natural, conocidos localmente como la Cañada y la Sierra Mazateca. En el primero de ellos se encontraban siete de los 26 pueblos del distrito con ayuntamiento, dos haciendas - Ayotla y Cuatempan- que fueron conjuntadas en 1887, así como media decena de ranchos, mientras que en la Sierra Mazateca se localizaban los restantes 19 pueblos, en un espacio en el que no existían haciendas ni ranchos.

El espacio situado al oeste del distrito, la Cañada teotiteca constituye una porción de lo que actualmente se conoce como el valle Tehuacán-Cuicatlán, el cual se extiende por aproximadamente 120 kilómetros -en dirección norte sur-, entre los municipios así denominados en los estados de Puebla y Oaxaca respectivamente. Su superficie, de alrededor de 636 kilómetros cuadrados, se encuentra a una altitud de entre 700 mil metros sobre el nivel del mar ( $\mathrm{msnm}$ ), y sus suelos son predominantemente semiáridos, con presencia de montes desérticos y vegetación de selva baja caducifolia. Su clima cálido ronda los $30^{\circ} \mathrm{C}$, y en meses como abril y mayo alcanza los $40^{\circ} \mathrm{C}$. Tal aspecto se complementa con el hecho de que su precipitación pluvial no supera los $700 \mathrm{~mm}$ de promedio anual, lo cual se debe a que los vientos húmedos provenientes del Atlántico, en dirección noreste, se detienen en los macizos montañosos de la Sierra Madre Oriental (Valiente-Banuet et. al., 2000), de la que forma parte la Sierra Mazateca. Debido a que en dirección opuesta está flanqueada por las montañas del norte de la Mixteca, la Cañada constituye una franja intermedia, cuyas tierras más bajas conforman una especie de vega en torno al río Salado. Éste corre de norte a sur unificando el líquido de numerosas corrientes torrenciales y permanentes procedentes de las mencionadas serranías de los flancos este y oeste, para dirigirse al río Grande-Papaloapan -del cual es una subcuenca-, que se dirige al Golfo de México. El río Salado toma su nombre de la alta salinidad que contienen sus aguas -a diferencia de la mayor parte de las otras corrientes con las que confluye cuyas aguas son dulces-. Este alto nivel de salinidad posibilitó que en algunos de los pueblos ahí situados se produjera sal desde la época prehispánica, y que incluso en el siglo XIX los ingresos por ese rubro siguieran siendo significativos. 
TABLA 1

Asentamientos de la Cañada y la Sierra Mazateca (pueblos, haciendas y ranchos), 1888-1915

\begin{tabular}{|l|l|}
\hline \multicolumn{2}{|c|}{ Asentamientos de la Cañada } \\
\hline \multicolumn{2}{|c|}{ Pueblos } \\
\hline 1 & Teotitlán del Camino \\
\hline 2 & San Martín Toxpalam \\
\hline 3 & San Antonio Nanahuatipac \\
\hline 4 & San Gabriel Casa Blanca \\
\hline 5 & San Juan Los Cues \\
\hline 6 & Santa María Tecomavaca \\
\hline 7 & Santa María Ixcatlán \\
\hline \multicolumn{2}{|c|}{ Haciendas } \\
\hline 1 & $\begin{array}{l}\text { Ayotla-Cuaute mpan } \\
\text { (conjuntadas en 1887) }\end{array}$ \\
\hline \multicolumn{2}{|c|}{ Ranchos } \\
\hline 1 & Xihuilapa (anexo a Cuautempan) \\
\hline 2 & Cuyulapa (anexo a Cuautempan) \\
\hline 3 & Calapilla (anexo a Cuautempan) \\
\hline 4 & Coamilco \\
\hline 5 & De la Cruz \\
\hline
\end{tabular}

\begin{tabular}{|l|l|}
\hline \multicolumn{2}{|c|}{ Asentamientos en la Sierra Mazateca } \\
\hline \multicolumn{2}{|c|}{ Pueblos } \\
\hline 1 & Santiago Texcalcingo \\
\hline 2 & San Pedro Ocopetatillo \\
\hline 3 & San Gerónimo Tecoatl \\
\hline 4 & Santa Cruz Acatepec \\
\hline 5 & Santa María Teopoxco \\
\hline 6 & San Lucas Zoquiapam \\
\hline 7 & San Francisco Huehuetlán \\
\hline 8 & San Lorenzo Cuaunecuicuitla \\
\hline 9 & San Cristó bal Mazatlán \\
\hline 10 & San Antonio Eloxochitlan \\
\hline 11 & Santa Ana Ateixtlahuaca \\
\hline 12 & Santa María Jiotes (la Asunción) \\
\hline 13 & San Mateo Huautla \\
\hline 14 & San Juan Huautla (de Jiménez) \\
\hline 15 & San Miguel Huautla \\
\hline 16 & San Juan Coatzompam \\
\hline 17 & San José Tenango \\
\hline 18 & Santa María Chilchotla \\
\hline 19 & San Bartolomé Ayautla \\
\hline
\end{tabular}

Fuente: elaboración propia con base en Martínez (1883, pp. 545-551)

El otro espacio de distrito, el de la Sierra Mazateca, de aproximadamente mil 680 kilómetros cuadrados, se compone de montañas zigzagueantes cuya altitud varía desde los mil 700 hasta los 3 mil msnm, característica que propicia que hacia su interior el clima predominante sea templado-frío. Esta característica se une a la de las precipitaciones pluviales, que son las más altas del país, al alcanzar el promedio anual de $2 \mathrm{mil} \mathrm{mm} \mathrm{de}$ lluvia (Neiburg, 1988, p. 29). En sus montañas se detienen las corrientes húmedas provenientes del Golfo de México, razón por la que extensas superficies de sus bosques de pino-encino-liquidámbar cuentan con elevada humedad, así como con nubes y neblina la mayor parte del año. En su interior, las diferencias naturales consisten en que el oeste serrano se conforma de una proporción más peñascosa y serpenteante, mientras que hacia el este, pueblos que lindan con el distrito de Tuxtepec, como Huautla, Santa María Chilchotla, San José Tenango y Ayautla cuentan con algunas superficies que, aunque boscosas, son más planas. Sus corrientes hídricas, como la del río Petlapa y otros que confluyen en el Tonto -otra subcuenca del Papaloapan-, son de una fisonomía distinta a la de los de la Cañada, ya que llegan a rondar los diez metros de ancho y su caudal es considerablemente más abundante (Bonilla, 2011, pp. 52-82).

La ubicación de las características naturales en ambos espacios nos permite establecer que cumplieron un rol central en el desarrollo de dinámicas productivas y de organización social distintas. Cynthia Radding (2005, pp. 455-456), por ejemplo, ha aludido a las tierras de frontera para referir espacios geográficonaturales cuya composición llega a delinear dinámicas disímiles entre los grupos humanos asentados en ellos, "ya sea como límites territoriales o como zonas de transferencia cultural". En la Cañada, dado su clima cálido y superficies semiáridas, el sistema de riego era indispensable para la agricultura y, por tanto, para la preservación de la vida social, por lo que se requería de organización para la captación, almacenamiento y distribución del vital líquido. Mientras tanto, también era constante la competencia por el agua y se suscitaban conflictos por ella entre los dueños de los trapiches-haciendas, ranchos y pueblos circundantes, como sucedía al menos desde el siglo XVII ${ }^{5}$. Debido a su orografía más plana, ese espacio se vinculó en mayor grado con el exterior, pues por ahí cruzaba la antigua vía que conectaba a la ciudad de Oaxaca con la de Tehuacán, la cual enlazaba sitios más distantes como Puebla y la capital del país por una parte, y Chiapas y Guatemala, hacia el sur (Acuña, 1984, p. 196). Por ello, al menos desde el siglo XVI, los vínculos de sus 
pueblos con el exterior fueron visibles. En la centuria siguiente, como parte de un proceso más amplio en que se establecieron trapiches azucareros desde Coxcatlán, Puebla, hasta Cuicatlán, Oaxaca (Motta y Velázquez, 2000; Motta, 2001; Motta, 2003), en sus tierras bajas circundantes al río Salado se estableció la hacienda de Ayotla, cuyo dueño, a fines del siglo XIX, instauró en ella un ingenio central tecnificado. Debido a ello, la élite local, predominantemente mestiza, se estableció en pueblos como Teotitlán, mientras que en otros circundantes había presencia de indígenas nahuas, mazatecos e ixcatecos. En los pueblos ahí situados, el idioma español ya estaba ampliamente difundido a finales del siglo XIX.

MAPA 1

Asentamientos del distrito de Teotitlán, Oaxaca en torno a 1900
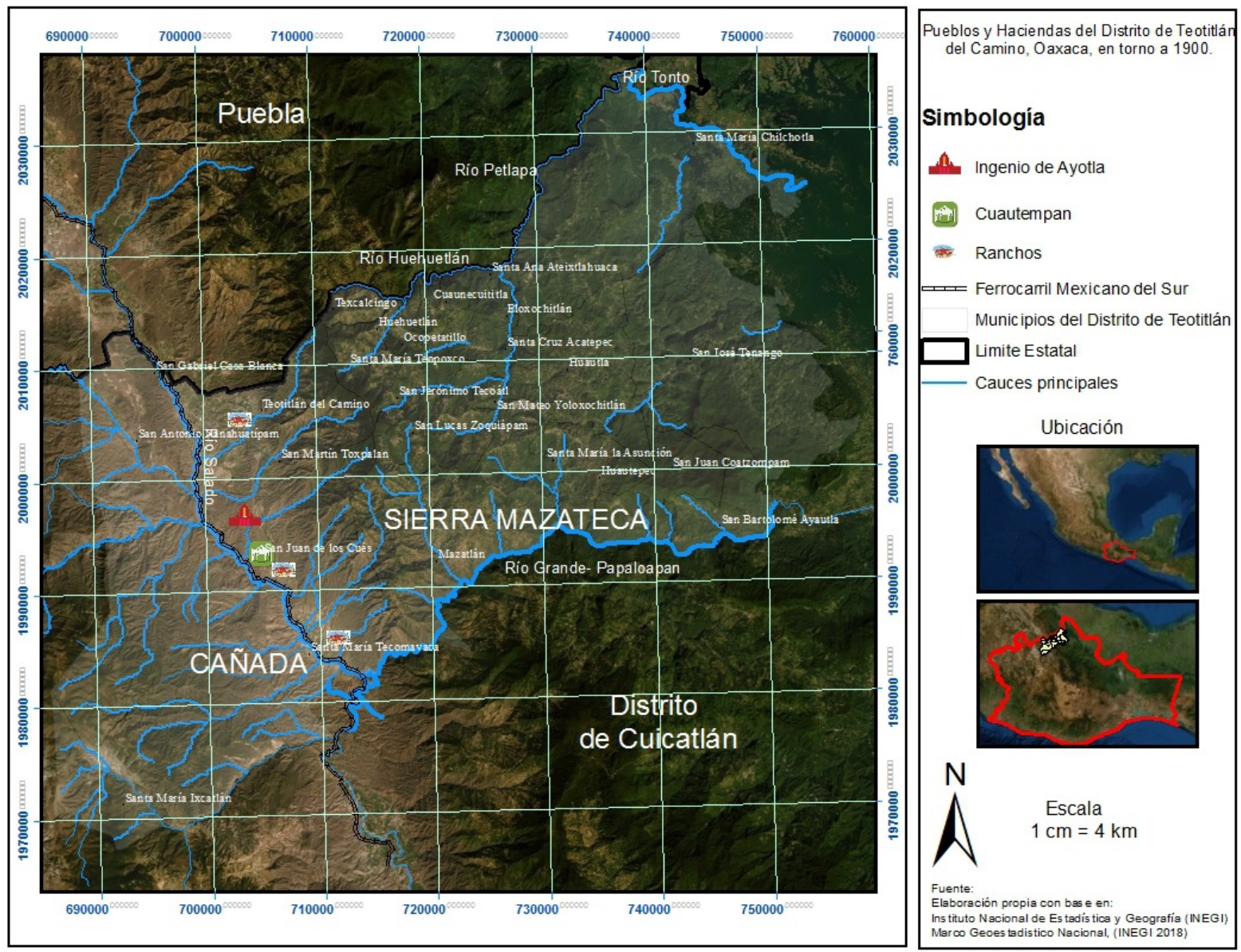

A su vez, en los asentamientos serranos el cultivo de mayor importancia era el maíz. Debido a la humedad, sus tierras contaban con mayor fertilidad, tal como se reportó desde la temprana época colonial (Acuña, 1984, p.196), característica que permitía a su población prescindir de sistemas captación y distribución de agua para riego. Una particularidad de ese espacio era que, como ha sido referido para otras superficies con características geográficas similares -por ejemplo en el estado de Oaxaca (Arrioja, 2011, p. 42)-, en algunos de esos pueblos sus habitantes cultivaban parcelas alejadas entre sí, ubicadas en variadas altitudes con el fin de aprovechar distintos pisos ecológicos y obtener diversas cosechas al año, mientras que para finales del siglo XIX pervivía el sistema de cultivo de roza, tumba y quema (Romero, 1893/2009:130), que habría sido imposible en parcelas permanentes ${ }^{6}$. A su vez, este espacio tenía menos vínculos hacia el exterior que la Cañada, debido, en alto grado, a su escarpada orografía rocosa y boscosa -como puede identificarse en el mapa 1-, así como a la carencia de caminos, o a que los mismos estaban en mal estado. Aún en las últimas décadas del siglo XIX ingenieros adscritos al gobierno federal registraban la imposibilidad para que bestias 
de carga transitaran ciertos tramos o ríos ${ }^{7}$. Debido a la anchura de algunos de éstos, sólo era posible cruzarlos mediante la instauración de troncos o puentes colgantes, lo cual permitía el paso de personas, pero no así el de burros o mulas. Esa característica influyó para que hasta la década de 1880 la sierra fuera escasamente visitada por actores externos, o que, dado el caso, al hacerlo tuvieran dificultades de diverso tipo, por ejemplo, la imposibilidad de comunicarse con la población indígena y sus representantes por falta de un idioma común ${ }^{8}$.

Tales diferencias denotan en alto grado la influencia del medio natural en las dinámicas sociales ahí suscitadas y cómo es que éstas se adaptan a las condiciones impuestas por sus características. Aún más, para nuestros fines resulta ilustrativo cómo la naturaleza incidió en el proceso de modernización que se intentó instaurar en el distrito teotiteco a fines del siglo XIX. En primera instancia, la legislación sobre aguas tuvo mayor relevancia en la Cañada, dado que ahí ese recurso era objeto de competencia y conflicto social, mientras que en la sierra prácticamente pasó inadvertida. En contraparte, los ordenamientos sobre división de tierras comunales se aplicaron en mayor grado en la sierra, debido a las posibilidades comerciales que otorgaban las ahí situadas por su alto potencial productivo. Ciertamente, a tal aspecto se sumaba el hecho de que las consideradas mejores superficies de la Cañada -las circundantes al río Salado- para el siglo XIX ya pertenecían a las haciendas de Cuautempan y Ayotla, por lo que quedaban fuera del objeto de los reglamentos sobre división y repartos, mientras que en la sierra los ayuntamientos seguían administrando amplias extensiones comunales. Como segundo factor, las características variadas del medio se complementaron con factores sociales -resistencias, conflictos, dificultades económicas- de modo tal que la mayoría de los grandes proyectos agroempresariales privados allí instaurados fracasaría durante las siguientes dos décadas. Obsérvese que la ubicación de la diversidad de los tipos de tierras -y lo que contienen- nos es de utilidad para no considerarlas homogéneas, ni tampoco a los recursos en ellas contenidos, así como para entender subsecuentes procesos disímiles con ellas relacionados. Así, a la pertinencia de cuestionarnos qué tipo de tierras son las que analizamos en los estudios agrarios -con el fin de entender qué ocurrió en ellas como consecuencia de las disputas por su control (Gallini, 2005, p.100) - se puede agregar la observación sobre los tipos de aguas existentes y utilizadas, lo cual aplica para el caso de la Cañada aquí analizado dada la presencia de corrientes con líquido salado y dulce en su interior.

\section{LA LEGISLACIÓN LIBERAL DECIMONÓNICA SOBRE TIERRAS Y AGUAS EN MÉXICO Y SU APLICACIÓN EN EL DISTRITO TEOTITECO}

El proyecto sociopolítico liberal del siglo XIX pretendía modernizar la sociedad mexicana distanciándose del antiguo régimen, al cual se relacionaba, entre otros aspectos, con la propiedad y el control comunal de tierras, aguas y bosques. En lugar de ello buscaba impulsar la instauración de la propiedad privada así como incrementar el control del gobierno federal sobre tales recursos. Hasta entonces, el país contaba con una población mayoritariamente indígena y campesina, la cual controlaba los recursos locales bajo el régimen comunal en un sinnúmero de pueblos, a través de sus ayuntamientos u otras instancias locales.

Con el fin de desarticular tal estructura, desde la década de 1820 varios gobiernos estatales retomaron el proyecto modernizador e ideológico de fines de la época colonial y ordenaron la desamortización de tierras comunales. Esto mismo, a nivel federal, se implementó mediante la Ley de desamortización de tierras civiles y eclesiásticas del 25 de junio de 1856 (Fraser, 1972; Knowlton, 1998), también conocida como Ley Lerdo. Con esa legislación se ordenó el reparto de propiedades que se encontraban bajo el control de la Iglesia así como el de las mencionadas tierras comunales de los pueblos, las cuales debían repartirse entre los vecinos y/o sus arrendatarios, y, luego de ello, las tierras sobrantes se otorgarían a posibles denunciantes interesados en ellas.

Por su parte, la primera ley referente al control de corrientes hídricas denominadas como federales se emitió el 5 de junio de 1888 bajo el título de Ley de vías generales de comunicación (Sánchez, 2003). En ella 
se estipuló que las aguas de los ríos que cruzaran o delimitaran varios estados, o al país con otros, pasarían a la jurisdicción del ejecutivo federal, el cual podría otorgar concesiones para utilizarlas, aspecto que se precisó en un reglamento de 1894 . Con sus propios matices, las reglamentaciones sobre aguas tenían un propósito similar al que perseguían las referentes a la desamortización de tierras comunales, pues pretendían desestructurar formas comunales de su control y distribución, centralizar su jurisdicción en el ámbito federal, y fomentar su utilización por parte del sector empresarial (Sánchez, 2003, p. 314).

No obstante, en la realidad esas leyes estuvieron muy lejos de aplicarse de manera general y automática. Si bien se instruyó la privatización de todas las superficies comunales, la percepción social sobre su valor productivo y económico influyó para que el estado en efecto emprendiera su privatización, para que fueran, o no, solicitadas en adjudicación, o para que los representantes o habitantes de los pueblos buscaran retenerlas o adjudicarlas. Situación similar puede observarse en el caso de las reglamentaciones sobre aguas, dado el interés económico que el estado tenía en su aplicación, según se ha señalado.

En el distrito tetotiteco la desamortización de tierras comunales fue apenas tenue durante los años previos a 1886. Incluso, paradójicamente, se dio el caso de que el ayuntamiento de San Antonio Nanahuatipam, situado en la Cañada, compró varias superficies a particulares y las incorporó a su régimen comunal -como sucedió en 1869 y $1876-$, en un acto que era contrario al propósito de la legislación federal ${ }^{9}$. Fue sólo a partir de los últimos años de la penúltima década decimonónica que las solicitudes de adjudicaciones se incrementaron en algunos pueblos de la Cañada -si bien no fueron numerosas-, aspecto en el que las condiciones naturales fueron de importancia. Por ejemplo, la media decena de denuncios que se realizaron en Teotitlán y San Juan los Cues entre 1886 y 1912 fueron sobre superficies que contenían fuentes de agua, recurso de valía en ese árido y cálido espacio. ${ }^{10}$

Por su parte, en la Sierra Mazateca la primera adjudicación atípica tuvo lugar en 1881, cuando se autorizó otorgar poco más de 144 hectáreas del paraje Río Santiago a un denunciante que, aprovechándose de su poder local, tomó más de 8 mil hectáreas, lo cual desembocó en un litigio entre los pueblos de Huautla, San José Tenango, y un par de particulares. El conflicto se resolvió 20 años después a favor del adjudicatario y del posterior comprador de esa superficie (García, 1955, p. 20). El resto de las adjudicaciones se otorgaron a partir de 1893, apenas un año después de la instauración del Ferrocarril Mexicano del Sur, que cruzó por la Cañada a una distancia de alrededor de 60 kilómetros de la Sierra Mazateca. Las fracciones serranas privatizadas fueron aquellas situadas al este, en las que existían más planicies y menos superficies pedregosas.

Dado que esos eran los años en que en el país se incrementaba sustancialmente el tendido de vías férreas, las exportaciones de materias primas así como las inversiones en general -proceso en el que Oaxaca participaba con dinámicas similares (Reina, 2004, pp. 147-166; Chassen, 2010)-, recursos naturales como los existentes en la sierra se tornaron más atractivos. Particularmente lo fueron para el cultivo de café, cuya producción y comercialización estaba siendo de importancia en distintas entidades del país como Veracruz, Chiapas, Colima, Michoacán y Oaxaca (Rodríguez, 2004, p.102; Bartra, 1996, p. 44). En ese último estado, su cultivo fue introducido en torno a 1870 por otrora productores de grana cochinilla de Miahuatlán, como consecuencia de la caída comercial del tinte a partir de la primera mitad del siglo XIX (Rojas, 1964, pp. 50-52), mientras que para la última década decimonónica su importancia iba en aumento, de modo tal que se producía en 16 de sus 26 distritos (Chassen, 2010, p. 191). A su vez, a aproximadamente 100 kilómetros al norte de la Sierra Mazateca, la ciudad de Córdoba, en el estado de Veracruz, había alcanzado notoriedad económica gracias a las cosechas y circulación comercial del grano, el cual se había introducido desde la tercer década decimonónica (Rodríguez, 2002). Aunado a ello, el paso del ferrocarril a una distancia de entre 70 y 110 kilómetros por las tierras bajas de la Cañada incentivó el interés de inversionistas foráneos por adquirir tierras en los pueblos serranos. El más atractivo de éstos fue Santa María Chilchotla, el cual era escasamente poblado debido a que sus poco menos de 500 habitantes en 1894 ocupaban una extensión aproximada de 394 kilómetros cuadrados, factor que debió incidir para que sus tierras se percibieran como disponibles ${ }^{11}$. Si bien hasta esa década sus representantes se habían opuesto a que sus superficies comunales se otorgaran 
a adjudicatarios foráneos, en 1893 cedieron a tal propuesta sólo pidiendo que cada jefe de familia, mayores de edad, y viudas del pueblo recibieran una parcela de 10 hectáreas de primera calidad, con riego, y otra de seis hectáreas de monte. Sin embargo, tal acuerdo les representó claras desventajas, toda vez que después de haber recibido las 16 hectáreas solicitadas, un total de 6 mil (10\%) permanecieron en manos de los vecinos, mientras que el resto, cerca de $30 \mathrm{mil}$ (90\%), se repartieron a alrededor de medio centenar de denunciantes externos $^{12}$. A partir de ese año de 1893, los cultivos cafetaleros se incrementaron sustancialmente, lo cual generó un cambio vertiginoso en el paisaje. Cientos de hectáreas del frondoso bosque serrano chilchoteco se sustituyeron por cafetales, los cuales incentivaron otros cultivos -maíz, frijol, hortalizas-, así como la cría de animales de traspatio y ganado para alimentar a dueños, administradores y cientos de trabajadores de las novedosas fincas. Aunado a ello, algunas fincas incluyeron cultivos comerciales como hule o arboles de naranja, además de la explotación de maderas finas ${ }^{13}$.

Ese fenómeno fue de menores proporciones en municipios como Tenango, Huautla y Ayautla, aspecto en el que pudo haber influido la ocupación de sus tierras, pues, como se ha apuntado, mientras en 1884 Chilchotla contaba con un territorio más extenso, que apenas era poblado por 490 individuos, en aquéllos había $1.660,4.319$ y 1.180 habitantes respectivamente ${ }^{14}$. Sin embargo, el cambio del paisaje social y natural en esos pueblos también fue significativo. En el primero de ellos se otorgaron por lo menos 12 mil hectáreas a un denunciante externo, mientras que en Ayautla, en 1903 fueron unificados dos lotes de mil hectáreas, adjudicados a los alemanes Bernardo Holtz y Carlos Scherer respectivamente, con otro, adjudicado al mexicano Agustín Pradillo, para instalar el cafetal Carlota, que llegó a ser uno de los más representativos de la sierra $^{15}$. En torno a 1902 -aunque ya propiedad de dueños sucesores, los norteamericanos de apellido Cookcontaba con casa para supervisores, edificios para alrededor de 500 trabajadores, una tienda y una panadería, y cultivaba alrededor de 170 mil matas de café, cuyo producto se enviaba a la ciudad de Chicago ${ }^{16}$.

Debido a ello, en pocos años la sierra mazateca alcanzó notoriedad en el ámbito nacional debido a la producción cafetalera, pues pasó de cosechar 73.600 kilos de grano en 1896, a 395.790 en 1906 (Chassen, 2010, p. 191). Así, acorde al ideal liberal que impulsó la desamortización, el valor de la tierra otrora comunal en la sierra se incrementó sustancialmente, a la vez que el cultivo de café se expandía a otros pueblos. En Santa Ana Ateixtlahuaca, por ejemplo - un pueblo en el que no fueron reportadas adjudicaciones en el mismo grado que en los pueblos del este serrano-, se instaló el cafetal La Reforma, del español Juan Lozano Alcalde, mientras que en Huautla, el denominado Nezahualcóyotl de la familia Gamboa ${ }^{17}$.

Para los habitantes serranos se trató de una década en que el discurso liberal y la política porfirista adquirieron facetas concretas que impactaron las relaciones sociales locales, debido al arribo de decenas de finqueros cafetaleros motivados por el paso del ferrocarril y por las facilidades para adquirir tierras. Eso generó novedosas interacciones entre los actores que ahí confluyeron a la vez que se gestaron algunos conflictos por límites de tierras entre pueblos y finqueros, así como entre indígenas locales que se emplearon con ellos. Este aspecto llegó a incidir en que las fincas adolecieran de "falta de brazos" 18 .

Mientras tal proceso tenía lugar en la sierra, en la Cañada también se gestaron expectativas productivas relacionadas con la legislación liberal. Desde 1887, año en que la concesión del Ferrocarril Mexicano del Sur ya estaba otorgada y en el cual seguramente las vías se encontraban en construcción, el exgobernador Ignacio Mejía, entonces dueño de la hacienda de Cuautempan, adquirió la contigua hacienda de Ayotla, con lo que unificó alrededor de 12 mil hectáreas de tierras, en la superficie más baja de ese espacio y en la que confluían preciadas corrientes hídricas con el río Salado ${ }^{19}$. A ello sumó la construcción del Ingenio Central de Ayotla, justo al pie de las vías del ferrocarril, con lo que cambió la provisión de agua del río San Martín, de aguas dulces, al Salado, de agua salobre, para el procesamiento de la caña ${ }^{20}$. Si bien existían ranchos vecinos productores de azúcar, alcohol y panela, como el de Coamilco, Xihuilapa y el de la Cruz, la nueva propiedad "Ayotla y anexas" adquirió especial relevancia al colindar con todos los pueblos ahí situados. Además, en el contexto político-económico que hemos referido, sus dueños -tanto Mejía como su sucesor Francisco 
Martínez Arauna- emprendieron la búsqueda de mayores volúmenes de agua con el fin de incrementar la producción cañero-azucarera. Una dificultad central para ello era que los pueblos circundantes estaban situados en superficies previas de corrientes como el Salado, el río Teotitlán y el San Martín, lo cual los perjudicaba durante coyunturas de conflicto, debido a la posible interrupción del paso del líquido. De hecho, ese era un aspecto que Ayotla compartía con los mencionados ranchos, los cuales a su vez estaban a expensas de que habitantes y representantes de San Gabriel Casa Blanca, Nanahuatipam y Tecomavaca no interfirieran el paso del agua, principalmente del río Salado.

Además, como sucedía en el caso del café, la producción cañera en el país incrementaba su importancia, mientras que en Oaxaca la que se obtenía en los distritos de Teotitlán y el contiguo de Cuicatlán llegó a ser la de mayor cuantía en la primera década del siglo XX (Ruiz, 1988, p. 342). Tal contexto pudo ser un aliciente para que los dueños de Ayotla consideraran que los problemas de obtención de líquido podían ser salvables. $\mathrm{Al}$ efecto, las estipulaciones sobre concesiones federales de aguas constituían una alternativa, ya que, en caso de obtenerlas, podrían solicitar que usuarios previos de las corrientes respetaran el volumen de líquido que el gobierno federal les otorgase, por lo que Mejía solicitó confirmación de derechos y concesiones de agua del río Salado en 1895 y 1900 respectivamente, mientras que su sucesor hizo lo propio en $1912^{21}$. Con base en tales motivaciones, Martínez Arauna incrementó las áreas de cultivo de caña por lo menos hasta 1907, cuando sumó a su propiedad las haciendas de Santa Tecla Tocomaxtlahuac y el rancho de Los Obos, situados en Cuicatlán, cuyas cosechas de caña procesaría en el Ingenio Central de Ayotla ${ }^{22}$.

Así, debido a la llegada de agroempresarios y su adquisición de tierras, y al incremento de la producción cafetalera y cañera, el distrito obtuvo cierta relevancia económica a nivel estatal, aspecto que se prolongó hasta la primera década del siglo XX. No obstante, en los años posteriores a 1906, ambos proyectos -el cañero y el cafetalero- declinaron. En este aspecto la naturaleza jugó un rol de importancia.

\section{EL DECLIVE DE LOS PROYECTOS AGROEMPRESARIALES EN EL DISTRITO TEOTITECO Y EL ROL DE LA NATURALEZA}

La ya señalada visión de la dominación del ser humano sobre la naturaleza que ha predominado en la Historia Ambiental es evidente también en los estudios que se han centrado en México. En los trabajos pioneros en la materia - como el de Elinor Melville (1999) sobre la introducción de la ganadería en el Valle del Mezquital en el período colonial, y los que se incluyeron en el primer tomo de estudios sobre historia y ambiente coordinado por Bernardo García y Alba González (1999) -, se han observado centralmente los cambios generados en el paisaje a partir de la explotación de recursos naturales como bosques, aguas, y otros, por parte de sectores sociales específicos. Si bien tal faceta ha sido de suma importancia para la comprensión de una amplia diversidad de relaciones hombre-naturaleza en marcos espacio-temporales, aún hemos observado poco el modo en que el medio ha incidido para suscitar, evitar o delinear procesos sociales particulares. Considero que tal perspectiva es de valía para entender el proceso decimonónico interrumpido- de modernización, que tuvo lugar en el distrito de Teotitlán del Camino, el cual ciertamente incluyó factores económicos y políticos.

En la Sierra Mazateca, el auge de las fincas privadas cafetaleras se experimentó aproximadamente hasta 1905, cuando se hizo evidente que dueños de algunas de ellas no alcanzaron sus expectativas económicas, por lo que vendieron sus propiedades; otros no pudieron pagar sus préstamos y fueron embargados, tal como sucedió con algunas fincas en el vecino distrito de Cuicatlán (Mendoza, 1998, pp. 142-143), o cayeron en bancarrota. No obstante, los datos relacionados con las finanzas de los finqueros no permiten identificar en qué grado la naturaleza habría incidido como una causa para tal situación. Esto se puede inferir al observar la incidencia de características orográficas y fenómenos climatológicos.

La prensa de fines del siglo XIX refería por ejemplo que la orografía serrana nunca pudo ser lo suficientemente adecuada (Chassen, 2010, p. 90), lo que había dificultado y encarecido el transporte de café hasta la estación del ferrocarril, en Nanahuatipam. A pesar de que el gobierno federal y el estatal realizaron 
obras para abrir y adecuar caminos donde fuera necesario, éstos siguieron siendo deficientes. $\mathrm{Al}$ respecto, los supervisores del Cafetal Carlota comunicaban en sus misivas a los dueños de la empresa en la ciudad de Chicago los no pocos problemas que les suponía el traslado de maquinaría o enseres desde las vías del tren hasta Ayautla -donde se encontraba el cafetal-. El trayecto consistía en atravesar alrededor de 100 kilómetros por una superficie agreste y húmeda, enfrentar frecuentes aguaceros, y eventualmente lidiar con la creciente de los ríos que cruzaban el camino ${ }^{23}$. Por su parte, algunos diarios reportaron que en julio de 1898 un "fuerte temporal" había dañado las parcelas y los caminos en los distritos de Cuicatlán y Tehuacán, incluido el que iba "para las fincas cafetaleras", lo que habría dañado su producción en algún grado ${ }^{24}$. A su vez, el finquero húngaro Eugenio de Banó escribió en su diario, en torno a 1903, que en tan sólo unos minutos había perdido su inversión y varios años de trabajo, debido a que, mientras realizaba un viaje a Teotitlán, un tornado había arrasado con su finca, su plantación y con todas sus pertenencias (Banó, 1906, pp. 337-340; Balázs, 2014, p. 202).

Otro caso representativo de bancarrota debido a eventos naturales fue el de Rito Mijangos, un próspero cafeticultor de la hacienda El Progreso -en Pochutla, Oaxaca-, a quien Armando Bartra (1996, pp. 111-120) considera como el que para fines del siglo XIX era el que obtenía mayores cosechas de grano en todo el estado. Atraído por las expectativas de la disponibilidad de tierras y de su alta productividad, Mijangos adquirió el lote Santa Elena, situado en Santa María Chilchotla a orillas del río Tonto, en torno a 1900, para lo cual hipotecó su próspera hacienda de Pochutla con la empresa inglesa Rosing Brothers. En dicho lote planeaba instalar un ingenio cañero aprovechando la corriente del Tonto como vía fluvial para el transporte de sus productos hacia Veracruz, mientras que en dirección opuesta utilizaría la ruta convencional, por tierra, hacia Teotitlán. Desde sus primeras acciones utilizó el mencionado río para transportar maquinaria para su prospectado ingenio, que había importado desde Inglaterra, y que había llegado al Puerto de Veracruz. No obstante, las intensas lluvias de esos días provocaron el desbordamiento de la corriente, de tal modo que la maquinaría se inundó sin que se hubiera podido hacer nada por rescatarla, al no poder ser jalada por bestias o por algún tipo de carro, debido a la imposibilidad de que pudieran arribar a aquel sitio. Según refiere Bartra, de tal evento el comprador de Santa Elena nunca pudo reponerse financieramente.

Aunado a ello, las plagas también afectaron a los cafetales serranos. En 1903, la denominada mancha de bierro arrasó con cultivos diversos y plantaciones en diversas regiones del estado, y sus efectos alcanzaron a la Sierra Mazateca ${ }^{25}$. En febrero de 1905, los jefes políticos informaron al gobierno estatal sobre las plantaciones que habían sido dañadas, reportes que incluyeron a los cafetales Cuauhtémoc, Gentiles y Clemencia, situados en Chilchotla, de los que se anotó que sus árboles estaban completamente dañados, por lo que la Comisión de Parasitología sugería quemarlos con el fin de evitar que contaminaran otras plantaciones ${ }^{26}$.

Si bien acciones políticas y económicas habían impulsado proyectos de gran envergadura en las superficies serranas, sus características naturales constituyeron un factor de importancia que no había sido contemplado ni por las autoridades ni por los propios inversionistas, o, en todo caso, se les había considerado de menor importancia. De tal modo, para 1913 el número de fincas era de 15 (Esteva, 1913, p. 27), y ya no más el medio centenar que se había constituido 20 años atrás. Para 1915 ya eran sólo excepcionales los finqueros cuya producción era sustancial. Uno de ellos era Antonio Avendaño, quien no sólo había conservado su finca La Soledad desde que la instaló en tierras adjudicadas en 1893, sino queademás había adquirido La Chicharra y Santa Herminia. En ellas, que en conjunto cubrían 2.233 hectáreas, producía hule además de café y utilizaba maquinaria importada para el procesamiento del grano $^{27}$. Avendaño era uno de los pocos adjudicatarios de 1893 que había persistido en la producción cafetalera. Durante los trámites de desamortización había colaborado como traductor - mazateco-españolcon las autoridades distritales, lo cual ilustra que era indígena mazateco, o, en todo caso, que había estado en contacto con esa población suficiente tiempo como para aprender el idioma, y por lo tanto ser un conocedor del medio natural serrano. 
Otro finquero que había sobrevivido a la debacle fue Manuel Gamboa, dueño del cafetal Nezahualcóyotl. Si bien él y sus hijos - con quienes administraba el cafetal-estaban radicados en el pueblo cabecera, conocían ampliamente a la Sierra Mazateca, toda vez que desde años previos habían adquirido o administrado otras fincas como el cafetal Mercedes ${ }^{28}$.

Un caso disímil a los previos es el del Cafetal Carlota -que también sobrevivió luego de 1910-, del que se ha apuntado que sus dueños a partir de 1899 fueron los empresarios norteamericanos hermanos Cook, quienes comercializaban sus cosechas de grano en la ciudad de Chicago y en otras urbes circundantes a través de una empresa que fundaron a tal efecto, la Cafetal Carlota Company ${ }^{29}$. Sin embargo, en un juicio que enfrentaron en una corte neoyorkina en 1912 se hizo público que en realidad esa finca se había sostenido principalmente por su esquema de financiamiento y no tanto por su producción ${ }^{30}$. Uno de los accionistas, Joseph G. Cushman, demandó a sus dueños acusándolos de prometer ganancias que no correspondían a la realidad. En lo que a él concernía, adquirió 25 mil dólares en acciones en enero de 1911, pero al poco tiempo la empresa se declaró en quiebra, por lo que perdió en ello su cuantiosa inversión. Por este suceso se entabló un juicio que finalmente perdió en 1914.

De esos hechos deducimos que una causa importante para que los finqueros foráneos cayeran en bancarrota fue su desconocimiento de las condiciones ambientales serranas. En contraste, es posible que la familiaridad de Avendaño y Gamboa con ese espacio haya sido de valía para su pervivencia como productores y comerciantes en el ramo.

A pesar de lo acaecido con la mayoría de las extensas fincas privadas, ese proceso marcó un cambio productivo y social en la sierra. La producción de café fue adoptada por las familias indígenas; gracias a ello, su cultivo y comercialización prosiguieron durante todo el siglo XX, e incluso, aunque en menor grado, hasta nuestros días. Si bien no se cuenta con datos cuantitativos que permitan ponderar las proporciones de sus cosechas respecto de las obtenidas por los finqueros, sí podemos inferir que desde esos años eran sustanciales. Por ejemplo, en sus remembranzas, el intermediario Guadalupe García (1955, pp. 27-30) escribió que entre 1906 y 1916 su negociación “Guadalupe García y hermano” obtuvo cuantiosas ganancias debido al paulatino incremento del grano que comercializaba, el cual a su vez compraba en alta proporción a productores a baja escala. Según refirió, en su comercio establecido en

Huautla, les recibía el grano cosechado en distintos pueblos serranos a cambio de productos que requerían, como abarrotes o semillas. De sus notas también se deduce que, como resultado de la mayor circulación comercial del café, habían emergido intermediarios -como él- que acaparaban la producción local y la comercializaban en el exterior, intercambio que no siempre se realizaba en términos equitativos. Por ejemplo, García se jactaba de que, a diferencia de otros comerciantes, él era honesto al pagar a los indígenas el "peso exacto" de su grano, en efectivo y al momento de la entrega (García, 1955, p. 27). Cierto es que una proporción del grano que adquiría procedía de fincas que había adquirido o arrendado, pero una parte sustancial la compraba a indígenas mazatecos, de tal modo que, según sus propios cálculos, trasladaba alrededor de 200 mil kilos mensuales de grano al ferrocarril, vehículo que a vez lo conducía tanto a mercados nacionales como del exterior (García, 1955, p. 27).

Podemos inferir que las causas centrales de la persistencia de las familias indígenas en el cultivo del grano se debió al conocimiento que tenían sobre el medio. También al hecho de que sus inversiones fueran de mucha menor cuantía que la de los finqueros, lo cual posibilitaba que, en caso de alguna calamidad, la pérdida de ellas no les representara una bancarrota definitiva. Aunado a ello, las familias serranas conservaron la costumbre de utilizar parcelas distantes entre sí o de sus caseríos (Incháustegui, 1967, p. 15), lo cual también disminuía los riesgos económicos de la pérdida de cultivos. Tampoco habrían buscado obtener grandes ganancias, lo cual les habría permitido mayor flexibilidad de producción, o que la complementaran con otros cultivos según sus propias necesidades. Esto último habría sido imposible para los finqueros privados, algunos de los cuales debían saldar deudas contraídas para instaurar o mantener sus cafetales, saldar gastos continuos, a alcanzar pingues ganancias. 
De igual modo, el crecimiento de Ayotla-Cuautempan en la Cañada enfrentaba dificultades económicas en la primera década del siglo XX, las cuales también estaban relacionadas con las características naturales de ese espacio. Esto resulta acorde a la perspectiva de la diferenciación de superficies y recursos naturales que hemos señalado (Gallini, 2005). La limitada disponibilidad de agua siguió impidiendo el incremento de su producción, y, por ende, de sus ganancias, lo que dio pie a una desproporción entre la inversión realizada en su infraestructura y la insuficiencia del vital líquido. Eso se debió a que los habitantes de los pueblos nunca dejaron de competir por ese recurso natural, ni en los tribunales ni en la vida cotidiana, aunque también la naturaleza jugó un rol de importancia. En un informe de 1923, un ingeniero adscrito a la Secretaría de Agricultura y Fomento -instancia del gobierno federal- reportó que la fertilidad de los campos de la hacienda estaba disminuyendo drásticamente, debido a que se tornaban más secos y a que se estaban ensalitrando ${ }^{31}$. Desde que el antiguo trapiche de Ayotla fue instalado en la parte baja de la Cañada sus dueños, los religiosos jesuitas regaban parte de sus campos con aguas del río Salado; los efectos de esta práctica-de por lo menos tres siglos- se hicieron evidentes cuando se intentó elevar su producción ensalitrando los campos. A saber, la capacidad para la producción cañera de las tierras de por sí semiáridas se empobreció aún más. Tal deficiencia productiva habría influido en alguna medida en la permanente búsqueda que los dueños de Ayotla realizaban de fuentes de agua, así como en la conflictividad que ello implicaba.

En conjunto, las dificultades por obtener agua constituyeron un factor central para el declive de esa hacienda, hecho que se sumó a dificultades financieras que llevaron a que su dueño, Francisco Martínez Arauna, no pudiera seguir pagando a partir de 1917 una hipoteca adquirida cinco años atrás con el gobierno federal, y a que finalmente le fuera confiscada su propiedad en la siguiente década ${ }^{32}$. En ese tiempo, comenzaron a conformarse varios ejidos posrevolucionarios en los pueblos circundantes, cuyo cultivo principal comenzaría a ser la caña de azúcar, la cual se trabajaría con el fin de vender la gramínea a ingenios cercanos (Wesley, 1967, p. 135). Un cambio social en el que la naturaleza también incidió.

\section{CONCLUSIONES}

En la historiografía en general, así como en la historia ambiental en particular, ha predominado la perspectiva sobre la posición privilegiada y de dominación del ser humano sobre la naturaleza, la cual se extiende a los análisis sobre la aplicación de las reformas liberales como las analizadas en este trabajo. En efecto, tal postura ha ilustrado complejas facetas sobre el devenir de diversos conjuntos sociales y espacios naturales. No obstante, ese cuadro de explicaciones aún puede completarse con ponderaciones sobre el modo en que la naturaleza ha posibilitado, o impedido, los procesos analizados, aspecto que se ha incluido en este artículo. En primera instancia se ha considerado que la aplicación de la legislación sobre tierras y aguas en el distrito teotiteco, un instrumento central de la modernización liberal, no fue homogénea ni abarcó a todas sus tierras y recursos por igual. Las características de sus espacios, aunadas a factores sociales -como la ocupación previa de las tierras o a su valoración según el contexto- y económicos fueron de importancia en la elección de las superficies y corrientes en que se buscó, o no, dividir las tierras comunales o apelar a la regulación federal de aguas. Como segundo aspecto, la naturaleza se conjugó con factores sociales y económicos para que los proyectos agroempresariales fracasaran tanto en la Cañada como en la Sierra Mazateca en torno a la primera y segunda década del siglo XX. En el primer espacio los dueños de la hacienda de Ayotla no pudieron acaecerse de más agua, mientras que la de composición salada menguó en algún grado la fertilidad de parte de sus campos. A su vez, en la Sierra Mazateca, calamidades climáticas o dificultades relacionadas con la orografía afectaron la pervivencia de las extensas fincas privadas.

Es necesario precisar que la naturaleza no impacta a todos los sectores de forma homogénea, lo cual representaría un determinismo absoluto sobre los seres humanos. Al igual que los actores sociales utilizan y 
explotan la naturaleza diferencialmente (Foladori, 2001; Toledo, 2013), éstos perciben y se desenvuelven de modo disímil ante ella, acorde a sus propios intereses y características sociales y culturales. Así se percibe en el hecho de que el cultivo de café persistió en la Sierra Mazateca posterior al declive económico de los dueños de extensas fincas, dado que fue adoptado por familias indígenas serranas que utilizaron sistemas productivos diferentes.

Esa explicación también aplica para lo acaecido en la Cañada, donde la gran propiedad privada de “Ayotla y anexas" no persistió hacia la década de 1920, período en que habitantes de varios pueblos circundantes ya habían adoptado la producción de caña, realizada en superficies que obtuvieron como ejidos "posrevolucionarios" expropiados a esa hacienda y a ranchos circundantes (Wesley, 1967, p. 135). En tales explicaciones, factores políticos y sociales han sido ilustrativos pero complementados sustancialmente con la observación del accionar de la naturaleza.

\section{REFERENCIAS}

Acuña, R. (1984). Relaciones geográficas del siglo XVI: Antequera, tomo II. México DF: Universidad Nacional Autónoma de México.

Arrioja, L. A. (2011). Pueblos de indios y tierras comunales. Villa Alta, Oaxaca, 1742-1856. Zamora: El Colegio de Michoacán.

Arrioja, L. A. (2012). "Enjambres" y "nubarrones" en el campo oaxaqueño: las plagas de langosta de 1802 y 1853. Relaciones, 129, 161-213. Recuperado de http://www.scielo.org.mx/pdf/rz/v33n129/v33n129a6.pdf

Balázs, V. (2014). "We are clearly deceive at home". Inter-American images and the depiction of Mexico in Hungarian travel writing during the second half of the nineteenth century (Tesis de Doctorado). Universidad de Debrecen, Debrecen, Hungría. Recuperado de https://dea.lib.unideb.hu/dea/bitstream/handle/2437/195956/Venkovits Dissert_Final_t.pdf?sequence=7\&isAllowed $=\mathrm{y}$

Bartra, A. (1996). México bárbaro. Plantaciones y monterias del sureste durante el Porfiriato. México DF: El Atajo ediciones-Secretaría de Agricultura y Ganadería-Museo Nacional de Culturas Populares.

Bonilla, E. (2011). Análisis sistémico de los efectos de la variabilidad climática en la infraestructura hidráulica de la cuenca del río Papaloapan (Tesis de Licenciatura), Universidad Veracruzana, Facultad de Ingeniería, Xalapa, México.

Camacho, G. (2015). De la desamortización a la reforma agraria, 1856-1930. Los pueblos y sus tierras en el sur del valle de Toluca. Toluca: Universidad Autónoma del Estado de México.

Chassen, F. (2010). Oaxaca, entre el liberalismo y la revolución. La perspectiva del sur (1867-1911). México DF: Universidad Autónoma Metropolitana-Universidad Autónoma Benito Juárez de Oaxaca.

De Banó, E. (1906), Bolyongásaim Amerikában, Budapest: Számos Képpel. Amerikában. Recuperado de https://dea .lib.unideb.hu/dea/handle/2437/97810

Escobar-Ohmstede, A. (2012). La desamortización de tierras civiles corporativas en México: ¿una ley agraria, fiscal o ambas? Una aproximación a las tendencias en la historiografía, Mundo agrario, 13(25). Recuperado de http:// www.mundoagrario.unlp.edu.ar/article/view/MAv13n25a09

Esteva, C. (1913). Nociones elementales de geografía histórica del estado de Oaxaca. Oaxaca: Tipografía San Germán Hermanos.

Falcón, R. (2006). El arte de la petición: rituales de obediencia y negociación. México, segunda mitad del siglo XIX, Hispanic American Historical Review, 86(3), 466-500. Recuperado de https://read.dukeupress.edu/hahr/article -abstract/86/3/467/35332/El-arte-de-la-peticio-n-Rituales-de-obediencia-y?redirectedFrom=fulltext

Fiege, M. (1999). Irrigated Eden. The making of an Agricultural Landscape in the American West. Seattle: University of Washington Press.

Foladori, G. (2001). Controversias sobre sustentabilidad. La coevolución sociedad-naturaleza, Zacatecas: Universidad Autónoma de Zácatecas. 
Foltz, R. (2003). Does Nature have historical agency? World History, Environmental History, and how historians can help save the planet, The History Teacher, 37(1), 9-28. Recuperado de https://www.researchgate.net/publication/274507471_Does_Nature_Have_Historical_Agency_World_ History_Environmental_History_and_How_Historians_Can_Help_Save_the_Planet

Fraser, D. (1972). La política de desamortización en las comunidades indígenas, 1856-1872, Historia Mexicana, 21(4), 615-652. Recuperado de https://historiamexicana.colmex.mx/index.php/RHM/article/view/2974/2481

Gallini, S. (2005). El ambiente entre representación y ecología. Un estudio de caso en Guatemala, siglo XIX, Varia Historia, 33, 76-104. Recuperado de http://www.scielo.br/scielo.php?pid=S0104-87752005000100005\&scrip $\mathrm{t}=$ sci_abstract\&tlng=es

García, G. (1955). La Sierra de Huautla en la gesta oaxaqueña: la soberanía de Oaxaca en los ideales de la Revolución; autobiografía, narraciones históricas y mi contribución a la unidad, impulso y superación de la cafeticultura. México DF: edición del autor.

García B., y González A. (1999). Estudios sobre historia y ambiente en América I, México DF: El Colegio de MéxicoInstituto Panamericano de Geografía e Historia.

Hugues, D. (2016). What is Environmental History? Cambridge: Polity Press

Knowlton, R. (1998). El ejido mexicano en el siglo XIX, Historia Mexicana, 48(1), 71-96. Recuperado de https://his toriamexicana.colmex.mx/index.php/RHM/article/view/2402/1928

Martínez, M. (1883). Colección de "Cuadros Sinópticos" de los pueblos, haciendas y ranchos del estado libre y soberano de Oaxaca, Oaxaca: Imprenta del Estado a cargo de I. Candiani.

Melville, E. (1999). Plaga de Ovejas, consecuencias ambientales de la conquista de México, México DF: Fondo de Cultura Económica

Mendoza E. (1998). Desamortización comunal y expansión agrícola en el distrito de Cuicatlán, Oaxaca, 1856-1910 (Tesis de Maestría). Instituto de Investigaciones Dr. José María Luis Mora, México DF, México. Recuperado de https://mora.repositorioinstitucional.mx/jspui/bitstream/1018/217/1/MOR000060675\%20Desamortiza ción\%20Comunal\%20y\%20Expansión\%20Agr\%C3\%ADcola.pdf

Mendoza E. (2011). Municipios, cofradías y tierras comunales. Los pueblos chocholtecos de Oaxaca en el siglo XIX. México DF: Centro de Investigaciones y Estudios Superiores en Antropología Social-Universidad Autónoma Metropolitana-Universidad Autónoma Benito Juárez de Oaxaca.

Molina A. (1909/2016), Los grandes problemas nacionales. Ciudad de México: Instituto Nacional de Estudios Históricos de las Revoluciones de México.

Nash, L. (2005). The agency of Nature or the nature of agency, Environmental History, 10(1), 67-69.

Neri, J. P. (2017). Entre montes y lagunas. Desamortización y mercado de tierras en la subcuenca del río Cuautitlán, 1856-1917 (Tesis de Doctorado). Centro de Investigaciones y Estudios Superiores en Antropología Social, Ciudad de México, México.

Neiburg, F. (1988). Identidad y conflicto en la sierra mazateca. El caso del Consejo de Ancianos de San José Tenango. México DF: Instituto Nacional de Antropología e Historia-Escuela Nacional de Antropología e Historia.

Pérez, L. A. (2001). Winds of Change. Hurricanes and the transformation of Nineteenth-Century Cuba, Chapell Hill: The University of North Carolina Press.

Radding, C. (2005). Paisajes depoder e identidad: Fronteras imperiales en el desierto de Sonora y Bosques de la Amazonia, México DF: Centro de Investigaciones y Estudios Superiores en Antropología Social-Universidad Autónoma Metropolitana-Azcapotzalco-El Colegio de Sonora.

Raymond B., y Falcón, R. (1998). Cuautitlán y Don Porfirio. En R. Buve y R. Falcón (Coords.), Don Porfirio presidente..., nunca omnipresente. Hallazgos, reflexiones, y debates. 1876-1911 (pp. 13-36). México DF: Universidad Iberoamericana.

Reina, L. (2004). Caminos de luz y sombra. Historia indígena de Oaxaca en el siglo XIX. México DF: Centro de Investigaciones y Estudios Superiores en Antropología Social-Instituto Nacional Indigenista. 
Rodríguez, M. (2002). La producción cafetalera mexicana. El caso de Córdoba, Historia Mexicana, 43(1), 81-115. Recuperado de https://historiamexicana.colmex.mx/index.php/RHM/article/view/2273/1891

Rodríguez, M. (2004). Fiscalidad y café mexicano. El porfiriato y sus estrategias de fomento económico para la producción y comercialización del grano (1870-1910), Historia Mexicana, 44(1), 93-128. Recuperado de https ://historiamexicana.colmex.mx/index.php/RHM/article/view/1414/2773

Rojas, B. (1964). El Café. Estudio de su llegada, implantación y desarrollo en el estado de Oaxaca. México DF: Sociedad Mexicana de Geografía y Estadística-Editorial Luz.

Romero, M. (1893/2009). El Cultivo del café en la república mexicana, Revista de Geografia Agrícola, 43, 110-171. Recuperado de http://www.redalyc.org/pdf/757/75715608009.pdf

Sánchez, M. (2003). La primera transferencia. Gestión y administración federal del agua en México. En P. Ávila (ed.) Agua, Medio Ambiente y Desarrollo en el Siglo XXI. México desde una perspectiva global y regional (pp. 311-320). México DF: El Colegio de Michoacán.

Schenk, F. (1995). La desamortización de las tierras comunales en el Estado de México (1856-1911). El caso del distrito de Sultepec, Historia Mexicana, 45(1), 22-39. Recuperado de http://smtp2.colmex.mx/downloads/bg257h03b

Scott, J. (1998). Seeing like a State. How certain schemes to improve the human condition have failed. Connecticut: Yale Univesity.

Servín, E. (2016). Frank Tannenbaum entre América Latina y Estados Unidos en la Guerra Fría, A contracorriente, 13(3), 50-75.

Stewart, M. (1991). Rice, water and power: landscapes of domination and resistance in the Lowcountry, 1790-1880, Environmental History Review, 15(3), 47-64. Recuperado de https://works.bepress.com/mart_stewart/8/

Tannenbaum, F. (1933). The peace by revolution: An interpretation of Mexico. Nueva York: Columbia University.

Tannenbaum, F. (1938). La paz por la revolución. Santiago de Chile: Ercilla.

Tannembaum, F. (2003). La pazpor la revolución. México: Instituto Nacional de Estudios Históricos de la Revolución Mexicana-Secretaría de Gobernación.

Toledo, V. M. (2013). El paradigma biocultural: crisis ecológica, modernidad y culturas tradicionales, Sociedad y ambiente, 1(1), 50-60.

Tortolero, A. (1996). Presentación: Historia, espacio y ambiente en el México Central. En A. Tortolero (Coord.), Tierra, agua y bosques: Historia y medio ambiente en el México central (pp. 9-48). México DF: Centre Francais d'Etudes Mexicaines et Centroaméricaines-Instituto de Investigaciones Dr. José María Luis Mora-Potrerillos Editores-Universidad de Guadalajara.

Valiente-Banuet, A., Casas A., Alcántara A., Dávila P., Flores-Hernández N., Arizmendi A., Villaseñor J., Ortega J. (2000). La vegetación del valle de Tehuacán-Cuicatlán, Boletín de la Sociedad Botánica de México, 67, 24-74. Recuperado de https://www.researchgate.net/publication/283722157_La_vegetacion_del_Valle_de_Tehuaca n_Cuicatlan

Wesley, E. (1967). The sugar central as an agency for the socio-economic development of small properties in the Valley of Tehuacan Mexico (Tesis de Maestría). Universidad de British Columbia, Vancouver, Canadá.

\section{Documentos}

Court of appeals 1918, vol. 118. Library of the city of New York, version en PDF.

\section{Notas}

1 La obra citada de Frank Tannenbaum, "La paz por la revolución", publicada por el Instituto Nacional de Estudios Históricos de la Revolución Mexicana en 2003, corresponde a la traducción de su texto en inglés "Peace by revolution: An interpretation of Mexico" (Columbia University Press), que salió a la luz en 1933. A su vez, su primera versión en español se publicó en Chile en 1938 (Editorial Ercilla). Los trabajos e ideas políticas de Tannenbaum fueron objeto 
de interés -aunque no siempre de simpatía-, así como de pronta circulación en México. Al respecto ver, por ejemplo, Servín (2016).

2 Esto no significa que los pueblos siempre hayan rechazado las estipulaciones sobre desamortización de tierras o las solicitudes de concesiones de aguas. Cuando así les convenía, realizaron expeditamente los trámites en cuestión. Ver, por ejemplo, Mendoza (2011) y Neri (2017).

3 En el último de esos estudios el autor hace referencia a "nichos ecológicos" (Neri, 2017, p. 39). Una diferencia con el de "pisos ecológicos" es que este concepto se relaciona con características naturales distinguidas por su altitud, mientras que el de nichos ecológicos hace referencia a poblaciones de especies naturales que subsisten en unidades ecológicas o ecosistemas (Martínez, 2013).

4 La versión del texto de Hughes fue consultada en formato electrónico Kindle, en el que el apartado sobre las narrativas “declensionists" corresponden a la posición 3484-3489.

5 Algunos ejemplos son las confrontaciones en la década de 1690 entre los dueños del trapiche de Ayotla y el pueblo de Teotitlán por el control de algunas fuentes de agua, Archivo General de la Nación (en adelante AGN), Tierras, vol. 149, exp. 5; y en esa misma década con el de San Martín Toxpalam por algunos manantiales, AGN, Tierras, vol. 151, exp. 3. Los conflictos de los hacendados-trapicheros con Toxpalam por ese recurso también fueron recurrentes en el siglo XVIII e inicios del XIX. AGN, Tierras, vol. 489, exp. 1; AGN, Tierras, vol. 1319, exp. 2.

6 Archivo General del Poder Ejecutivo del Estado de Oaxaca (en adelante AGPEEO), Gobierno de los distritos, Contribuciones, leg. 12, exp. 8; AGPPEO, Gobierno de los distritos, contribuciones, leg. 12, exp. 32.

7 AGPEEO, Repartos y adjudicaciones, leg. 30, exp. 8.

8 AGPEEO, Repartos y adjudicaciones, leg. 30, exp. 8.

9 AGPEEO, Gobernación, gobierno de los distritos, leg. 29, exp. 49; AGPEEO, Gobierno de los distritos, tierras, leg. 34, exp. 14.

10 AGPEEO, Conflictos por tierras, leg. 77, exp. 20; AGPEEO, Repartos y adjudicaciones, leg. 26, exp. 16; AGPEEO, Repartos y adjudicaciones, leg. 26, exp. 18; AGPEEO, Periodo revolucionario, leg. 22, exp. 32.

11 AGPEEO, Gob. de los dtos, estadística, leg. 20, exp. 40.

12 AGPEEO, Repartos y adjudicaciones, leg. 27, exp. 1, f. 38 bis.

13 AGPEEO, Catastro, leg. 265, carpeta 2.

14 AGPEEO, Gob. de los distritos, estadística, leg. 20, exp. 40.

15 AGPEEO, Repartos y adjudicaciones, leg. 26, exp. 6. 16

17 AGPEEO, Repartos y adjudicaciones, leg. 26, exp. 1

18 CHHM, George Cook Company, Caja 3, folder 3, Wilbur Cook a Edlo MacClue, 13 de agosto de 1901.

19 AGPEEO, Repartos y adjudicaciones, leg. 26, exp. 13.

20 Archivo Histórico del Agua (en adelante AHA), Aprovechamientos superficiales, caja 946, exp. 13399, f. 113.

21 AHA, Aprovechamientos superficiales, caja 946, exp. 13399; AHA, Aprovechamientos superficiales, caja 946, exp. 13398.

22 AHA, Aprovechamientos superficiales, caja 946, exp. 13399, f. 168; AGN, Caja de préstamos para obras de irrigación y fomento de la agricultura, caja 47, exp. 191.

23 CHHM, George D. Cook, Caja 2, folder 4, 3 de diciembre de 1901, Wilbur Cook a George Shaw Cook.

24 El Nacional, Oaxaca, Ecos breves, 2 de julio de 1898.

25 Sobre la plaga "mancha de hierro", Basilio Rojas (1964:29-30) apunta que es una enfermedad "producida por un hongo (Omphalia Flabida, Mab) que se presenta en las hojas, formando una mancha café al principio y que pocos días después se vuelve blanca, teniendo en el centro un punto obscuro (...), generalmente se presenta en la época más lluviosa del año, en las temporadas de grandes aguaceros cuando existe una humedad muy intensa en el ambiente, desarrollándose con mucha fuerza y con una gran rapidez, pues no solo tira las hojas del cafeto sino también el grano (...)".

26 AGPEEO, Fomento, leg. 3, exp. 2, f. 97. Sobre otros casos de plagas ver Arrioja (2012).

27 AGPEEO, Catastro, leg. 265.

28 AGPEEO, Catastro, leg. 264.

29 CHHM, fondo George Cook Company.

30 Court of appeals, pp. 929-933.

31 AHA, Aprovechamientos superficiales, caja 2821, exp. 39408, ff. 157-158.

32 AGN, Caja de Préstamos, caja 47, exp. 191, s.n.

16 Chicago History Museum (en adelante CHHM), George Cook Company, Caja 3, folder 3, Wilbur, "E. Cook a Geo Shaw Cook", 21 de agosto de 1901; CHHM, George D. Cook, Caja 1, folder 5, "Wilbur Cook a George Shaw Cook", 23 de octubre de 1902. 